\title{
Radiological evaluation of low-grade glioma: time to embrace quantitative data?
}

\author{
Asgeir Store Jakola ${ }^{1,2,3}$ (D) Ingerid Reinertsen ${ }^{4}$
}

Received: 11 December 2018 / Accepted: 19 December 2018 / Published online: 29 January 2019

(C) Springer-Verlag GmbH Austria, part of Springer Nature 2019

The imaging modality that most of us rely upon in the management of the diffuse low-grade glioma (LGG) is MRI, with T1, T1 contrast enhanced, T2/FLAIR, perfusion and diffusion weighted imaging being the minimum core [4]. In addition to assess image appearance at a time point using different MRI sequences, the longitudinal information may also provide relevant information. The typical LGG is characterized by continuous slow and infiltrative growth $[10,12]$. In cases where the diagnosis is unclear the radiological demonstration of growth may guide treatment decisions. In addition, some centers still want to establish growth of a suspected LGG prior to referral to neurosurgery or before surgical resection, even though the traditional "wait-and-scan" until malignant transformation should clearly be avoided [8]. For these purposes, reliable measurement of growth is key. However, the routine assessment of lesion volume or even lesion diameter is lacking in many institutions. This may lead to underestimation of growth dynamics, as demonstrated by Gui and colleagues in this issue of Acta Neurochirurgica [5]. The radiologists reported "growth" when there was more than $20 \%$ increase of the volume. So called "stable lesions" were associated

This article is part of the Topical Collection on Tumor-Glioma

Asgeir Store Jakola

Jakola.asgeir@gu.se

Ingerid Reinertsen

Ingerid.Reinertsen@sintef.no

1 Department of Neurosurgery, Sahlgrenska University Hospital, Blå Stråket 5, 41345 Gothenburg, Sweden

2 Institute of Neuroscience and Physiology, University of Gothenburg, Sahlgrenska Academy, Gothenburg, Sweden

3 Department of Neurosurgery, St.Olavs University Hospital, Trondheim, Norway

4 SINTEF Digital, Health Research, Trondheim, Norway with approximately $10 \%$ increase in volume. This disturbing finding is in line with our previous report [7].

Why do we continue with this hazardous practice of qualitative growth estimation in LGG? Gui and colleagues clearly demonstrate that measurements based upon one or two diameters are inaccurate, but use of three diameters and an ellipsoid formula correlates reasonably well with the segmented volume [5]. Manual segmentation by a neuroradiologist may be the gold standard for assessment of tumor volume, but manual segmentation is also subject to even intra-rater variability [1]. There are several solutions and software available for both manual and semi-automated volume measurements, but these are often poorly integrated with the clinical radiological software and the clinical workflow. We realize that there is a learning curve and some variability of measurements, but believe the main obstacle with these techniques are the increased time needed for evaluation. These methods are simply too timeconsuming for routine clinical use. This does not fit well in with ideas of increased efficiency in every aspect of patient care.

We believe the solution for clinical application of quantitative volume measurement of LGG (and other tumors) lies within automated analysis. In the paper by Gui and colleagues we would have liked to see how available algorithms for tumor segmentation performed compared to the other methods. This lacking part would have made the paper not only looking back at already outdated techniques (e.g., one-dimensional diameter) but also provide a peak of what is to come. One obvious advantage of automated volume segmentations is the low variability of the same measurement (i.e., high precision). High precision is of special importance when performing relative measurements such as assessment of tumor growth over time, as high variability has the potential to hide the true difference between timepoints.

Automatic segmentation of brain tumors is an active field of research, and the yearly Brain Tumor Segmentation (BraTS) challenge enables direct benchmarking of the most recent developments [2]. Most recent automatic algorithms based on deep neural networks produce high accuracy 3D segmentations 
within seconds. The 2018 winner of the BraTS challenge used convolutional neural network and achieved average dice of 0.8839 for whole tumor segmentation [11]. One of the main limitations to the progress of automated brain tumor segmentation has been the lack of available data for training and validation, and the slow adaption and implementation by suppliers of clinical radiological software. The gap between methods that are well established in the research community and methods available for routine clinical use is still surprisingly wide. The argument is often being that these methods are not validated for clinical use. As shown by Gui and coworkers, methods that are in routine clinical use are not necessarily highly accurate and precise either. More available training data, well-defined validation requirements, and faster implementation of new methods by commercial suppliers (e.g. PACS systems) are the ways forward.

We are convinced that the current interest from the medical community with respect to deep learning will create solutions that are better than the current practice [3,9]. In addition to provide the volume of the LGG, routine LGG segmentation may also be crucial for the active use of other decision support tools like resection probability maps [6]. Brain tumor patients deserve and expect high quality assessment of their disease and with the current automatic algorithms, physicians, and researchers should not accept sub-optimal measurements produced by outdated methods.

Funding information This study was financially supported by the Vetenskapsrådet (2017-00944).

Publisher's note Springer Nature remains neutral with regard to jurisdictional claims in published maps and institutional affiliations.

\section{References}

1. Bo HK, Solheim O, Jakola AS, Kvistad KA, Reinertsen I, Berntsen EM (2017) Intra-rater variability in low-grade glioma segmentation. J Neuro-Oncol 131:393-402. https://doi.org/10. 1007/s11060-016-2312-9
2. BraTS website. http://braintumorsegmentation.org. Accessed 11.12. 2018

3. Chen JH, Asch SM (2017) Machine learning and prediction in medicine - beyond the peak of inflated expectations. N Engl J Med 376:2507-2509. https://doi.org/10.1056/NEJMp1702071

4. Freyschlag CF, Krieg SM, Kerschbaumer J, Pinggera D, Forster MT, Cordier D, Rossi M, Miceli G, Roux A, Reyes A, Sarubbo S, Smits A, Sierpowska J, Robe PA, Rutten GJ, Santarius T, Matys T, Zanello M, Almairac F, Mondot L, Jakola AS, Zetterling M, Rofes A, von Campe G, Guillevin R, Bagatto D, Lubrano V, Rapp M, Goodden J, De Witt Hamer PC, Pallud J, Bello L, Thome C, Duffau H, Mandonnet E (2018) Imaging practice in low-grade gliomas among European specialized centers and proposal for a minimum core of imaging. J Neuro-Oncol. https://doi. org/10.1007/s11060-018-2916-3

5. Gui C, Lau JC, Kosteniuk SE, Lee DH, Megyesi JF (2019) Radiology reporting of low-grade glioma growth underestimates tumour expansion. Acta Neurochir (Wien)

6. Hendriks EJ, Idema S, Hervey-Jumper SL, Bernat AL, Zwinderman AH, Barkhof F, Vandertop WP, Mandonnet E, Duffau H, Berger MS, De Witt Hamer PC (2018) Preoperative resectability estimates of nonenhancing glioma by neurosurgeons and a resection probability map. Neurosurgery. https://doi.org/10. 1093/neuros/nyy487

7. Jakola AS, Moen KG, Solheim O, Kvistad KA (2013) "No growth" on serial MRI scans of a low grade glioma? Acta Neurochir 155: 2243-2244. https://doi.org/10.1007/s00701-013-1914-7

8. Jakola AS, Skjulsvik AJ, Myrmel KS, Sjavik K, Unsgard G, Torp SH, Aaberg K, Berg T, Dai HY, Johnsen K, Kloster R, Solheim O (2017) Surgical resection versus watchful waiting in low-grade gliomas. Ann Oncol 28:1942-1948. https://doi.org/10.1093/annonc/ $\operatorname{mdx} 230$

9. LeCun Y, Bengio Y, Hinton G (2015) Deep learning. Nature 521: 436-444. https://doi.org/10.1038/nature14539

10. Mandonnet E, Delattre J-Y, Tanguy M-L, Swanson KR, Carpentier AF, Duffau H, Cornu P, Van Effenterre R, Alvord EC, Capelle L (2003) Continuous growth of mean tumor diameter in a subset of grade II gliomas. Ann Neurol 53:524-528. https://doi.org/10.1002/ ana. 10528

11. Myronenko A (2018) 3D MRI brain tumor segmentation using autoencoder regularization. arXiv preprint arXiv:181011654

12. Zetterling M, Roodakker KR, Berntsson SG, Edqvist PH, Latini F, Landtblom AM, Ponten F, Alafuzoff I, Larsson EM, Smits A (2016) Extension of diffuse low-grade gliomas beyond radiological borders as shown by the coregistration of histopathological and magnetic resonance imaging data. J Neurosurg 125(5):1-12. https://doi.org/10.3171/2015.10.jns15583 